\title{
Vertical Integration and Shared Facilities in Unregulated Industries*
}

\author{
Felipe Balmaceda ${ }^{\dagger}$ \\ Centro de Economía Aplicada-University of Chile \\ Eduardo Saavedra \\ Economics Department-Alberto Hurtado University
}

May, 2003

\begin{abstract}
Keywords: Shared-facilities, Vertical integration, Foreclosure
\end{abstract}

JEL Classification: D43, D61, L22, L13, L41, L42

\begin{abstract}
In this paper we consider a market situation in which initially there is an unintegrated monopoly upstream that owns an important facility and two dowstream firms. Then the market is liberalized allowing upstream entry and vertical integration. The equilibrium entry mode-sharing the incumbent facility or building a new facility-is derived as well as the equilibrium market structure. Several policy prescriptions are set forth.
\end{abstract}

\footnotetext{
${ }^{*}$ We are grateful to two anonymous referees and Ian Gale for their useful. We would like also to thank seminar participants at ILADES, Catholic University of Chile, the University of Chile, and the 2002 Latin American Econometric Society Meeting. However, all errors remain our own responsibility.

${ }^{\dagger}$ Correspondence to: Republica 701, Santiago Zip Code 6521122, Chile. E-mail: fbalmace@dii.uchile.cl .
} 


\section{Introduction}

There is an increasing worldwide trend to liberalize markets and introduce competition for services that were previously provided by monopolists. Markets like electricity, railways, telecommunications, water, oil and gas supply, airports and ports, garbage collection services, and stadiums are now open to competition. A common feature in all these markets is the presence of an "important facility", where this term is used to describe an infrastructure which is essential to reach customers and/or enabling competitors to carry on their business and cannot be easily duplicated. ${ }^{1}$ In addition, the trend towards liberalization and the introduction of competition in markets with important facilities have in many cases resulted in vertical integration processes that have led the owners of these facilities to become directly involved in serving final customers. ${ }^{2}$ For instance, it is now common to see port operators integrated with shipping companies, oil and natural gas transportation companies integrated with distribution companies, and hospitals and/or health plans affiliating with medical clinics and physicians.

Economists and antitrust authorities have long been concerned with vertical integration in markets with important facilities based on the belief that the owner of a facility has an incentive to engage in anticompetitive behavior, mainly foreclosure. ${ }^{3}$ Foreclosure states that the owner of an important facility has an incentive to limit competitors' access to its facility and

\footnotetext{
${ }^{1}$ Here, we do not focus on essential facilities as defined on some antitrust cases. For instance, in Alaska Airlines, Inc vs. United Airlines, Inc. (1991) an essential facility is defined as follows: "[A] facility controlled by a single firm will be considered "essential" only if control of the facility carries with it the power to eliminate competition...."

${ }^{2}$ In some industries and some countries liberalization and competition have been introduced under mandatory unbundling while in others have not. For instance, the introduction of competition in UK and the US natural gas market was under mandatory unbundling of all segments in the former case and separation of production and transportation in the latter case. In contrast, in Chile and New Zealand no unbundling requirement was imposed. The focus of the paper is in those experiences where there is no mandatory unbundling.

${ }^{3}$ The exception being the Chicago School led mainly by Bork (1976) and Posner (1978), who believe that foreclosure resulted from a confusion about the exercise of monopoly power. They argued that a monopoly owning an important or essential facility could earn monopoly profits in the corresponding segment, but could not extend its market power to related segments.
} 
monopolize complementary or downstream segments as well. ${ }^{4}$ Foreclosure was first discussed in the Terminal Railroad Association vs. United States (1912), in which a set of railroads acquired a key bridge over the Mississippi river and approaches and terminals in St. Louis and excluded other competitors. Foreclosure was also invoked in Aspen Skiing Company vs. Aspen Highlands, in which all-Aspen six-day ticket was offered, and revenues from those sales were divided based on usage from 1962 to 1977. After 1978 Aspen Skiing decided to continue with the agreement only if Aspen Highlands was willing to accept a $13.2 \%$ fixed share of ticket revenues.

The introduction of competition in markets in which initially there is an incumbent monopoly that owns an important facility requires access "on reasonable terms" to the incumbent's facility. An obvious alternative to access "on reasonable terms" is that the entrant builds its own facility. ${ }^{5}$ While there are definite savings associated with sharing the incumbent's facility when the latter has excess capacity, our worry is that the incumbent's incentives to integrate vertically and to share its facility with an entrant may have certain anticompetitive effects that are not usually recognized. In this article we mainly explore the possibility that the monopoly's offer to share its facility with a potential entrant might be a strategic decision aimed at forestalling a more complete and competitive entry and changing the incentives to foreclose competitors.

In so doing, we consider a market situation in which initially there is an unintegrated monopoly upstream that owns an important facility and two downstream firms. ${ }^{6}$ Then the

\footnotetext{
${ }^{4}$ The essential facility doctrine, which is one long-standing exception to the general US antitrust law's rule that a firm has no obligation to deal with its competitors, is concerend with foreclosure. As stated by one appellate court in Alaska Airlines, Inc, vs. United Airlines (1991): "[T]he essential facility doctrine imposes liability when one firm, which controls an essential facility, denies a second firm reasonable access to a product or service that the second firm must obtain in order to compete with the first."

In the case Associated Press v. United States (1945) the doctrine was interpreted as "a business or group of businesses which controls a scarce facility has an obligation to give competitors reasonable access to it."

${ }^{5}$ What usually makes an important facility different from an essential facility is the fact that the former can be duplicated while the latter cannot.

${ }^{6}$ In this paper we focus on industries where network externalities, consumption externalities, switching costs, and lock-ins are not relevant.
} 
market is liberalized meaning that upstream entry and vertical integration are now allowed. ${ }^{7}$ In particular, there is a potential upstream entrant that chooses between two entry modes, entering the market by building its own facility, paying a fixed cost (full entry, hereafter) or by buying capacity from the incumbent at a fixed price per-unit of capacity ${ }^{8}$, determined endogenously by bargaining with the incumbent (partial entry, hereafter).

We can think of downstream production as taking one unit of the intermediate good and selling it, while upstream production of the intermediate good requires a unit of capacity coming from a facility. The entrant's facility is assumed to be at least as efficient as the incumbent's facility; that is, the entrant's upstream marginal cost is lower than or equal to the incumbent's upstream marginal cost. Upon entry the incumbent and the entrant both have the opportunity to acquire one of the downstream firms; i.e., upstream firms choose simultaneously whether to integrate vertically or not. After the industry structure is determined, upstream firms decide how much of the intermediate good to produce, followed by downstream firms' decision of how much of the final output to produce. That is, upstream as well as downstream firms are assumed to compete a-la-Cournot.

The results are as follows. When the entrant chooses a full entry mode, both upstream firms choose to integrate vertically. When the quantity of input traded between a non-integrated firm and an integrated firm is determined endogenously without a priori restrictions on the direction of trade, as done in this paper, integration induces the integrated firm to buy up some of the non-integrated upstream firm's output to raise the costs of its non-integrated downstream rival. This is known as a raising rival cost strategy (see, Salop and Scheffman, 1987). Thus, vertical integration is a dominant strategy for each firm since it avoids double marginalization and counters its rival's incentive to buy up input from the non-integrated upstream firm. When the

\footnotetext{
${ }^{7}$ We do not consider the closely related access issues in regulated industries. In such industries, price controls and explicit or implicit earnings schemes often create incentives for regulated firms to engage in practices, such as cross-subsidies and degradation of quality, which are less important in an unregulated industry.

${ }^{8}$ We do not allow general non-linear pricing. As suggested by one referee, a justification for linear pricing is the imposition of non-discriminatory open access. In that sense, the model considered here can be thought of as one in which the only regulation is non-discriminatory open access.
} 
entrant chooses a partial entry mode, vertical integration continues being a dominant strategy despite the fact that the gains from selling excess capacity are larger when the incumbent does not integrate. Thus, the efficiency gains from avoiding double marginalization and counters its rival's incentive to buy up input from the non-integrated upstream firm outweigh the extra gains from selling more units of capacity.

When the mode of entry is endogenously determined, the industry equilibrium is as follows. For a low fixed cost of building a new facility, the entrant builds a facility and both the entrant and the incumbent integrate vertically. Whereas for a large fixed cost, the incumbent shares its facility with the entrant, and both integrate vertically. In addition, the amount of final good produced is larger under full entry. Thus, partial entry is anticompetitive relative to full entry since it forestalls a more competitive entry mode (full entry) and decreases the efficiency gains from vertical integration.

Partial entry however is pro-competitive relative to no entry; i.e., under partial entry the total amount produced is larger than that before liberalization, and sometimes stops full entry that may have not been socially efficient due to duplication of fixed costs. The welfare effects are as follows. When the difference between upstream marginal production costs is large, full entry is always efficient relative to partial entry, yet it is not always observed. In addition, when full entry is observed, it is efficient. Whereas when the difference between upstream marginal production costs is small, partial entry is efficient for fixed cost levels in an intermediate range, while full entry is efficient for either small or large fixed cost levels. That full entry is efficient for small fixed cost levels is relatively obvious, but that full entry is also efficient for large fixed cost levels is not. The reason being that the price per-unit of capacity rises at an increasing rate with the fixed cost level. This implies that for a large fixed cost level the decrease in consumers' welfare outweighs the increase in the incumbent's profit and the fixed cost saving from avoiding duplication of facilities.

These results have interesting policy prescriptions. Before specifying those, it is worthwhile noting that the policy prescriptions suggested here should be qualified by the fact that we consider only two different entry modes, no collusion is assumed, non-linear pricing of capacity 
is not allowed, and the incumbent cannot degrade the quality of access to its facility. That said, the policies are the followings. First, duplication of facilities with full vertical integration is procompetitive and efficient. This means that when a market is liberalized, competition authorities should not oppose to duplication of facilities and vertical integration. Second, under partial entry vertical integration by the incumbent cannot always be associated with a more restrictive access to the incumbent's facility. Third, it is usually believed that when the owner of a facility charges a competitor a different price than what it charges itself, it is acquiring an exclusionary right to the facility that can endow it with market power. However, our results suggest that when the cost of building a new facility is neither too large nor too small, it is efficient, relative to full entry, to charge a price above upstream marginal cost of production. Fourth, when the cost of building a new facility is very large, full entry is efficient relative to partial entry because under partial entry the incumbent monopoly charges too much for access to its facility, which in turn, results in a large final output restriction. An important lesson from these policy prescriptions is that the market itself is able in many situations to efficiently solve the trade-off between saving fixed costs and soften downstream competition.

The results are also in line with the spirit of the U.S. Federal Trade Commission and Department of Justice guidelines for collaboration among competitors issued on April, 2000. Mainly, this establishes that production collaborations “...may involve agreements jointly to produce a product sold to others or used by the participants as an input. Such agreements are often procompetitive. [...] However, production collaborations may involve agreements on the level of output or the use of key assets, or on the price at which the product will be marketed by the collaboration, or on other competitive variables such as quality, services or promotional strategies, that can result in competitive harm". ${ }^{9}$

The results also provide a rationale for liberalization of industries having certain characteristics of natural monopoly as a complement, if not as an alternative to direct regulation. In fact, unregulated privatization becomes a relevant policy design under facility based competition. In practice, however, to which industries this policy can be applied is a question that demands a

\footnotetext{
${ }^{9}$ See section 3.31a, FTC (2000).
} 
case by case analysis that is beyond the scope of this paper.

Because our paper combines the literature on vertical integration with that concerning the sharing of facilities, there are, as far as we know, no papers dealing exactly with the same issues. ${ }^{10}$ In general terms our paper departs from the vertical integration literature in that it considers an endogenous choice of mode of entry. And it also departs from the literature on sharing facilities in that it allows for an endogenous choice of market structure.

Chen and Ross (2000), which is closely related to this paper, show that in a monopolistic market a shared-facility agreement may deter a more aggressive entry that reduces the incumbent's market power, yet a shared facility always results in a larger output than the one chosen by a monopoly but less than when the entrant builds its own facility. ${ }^{11}$ Gale (1994) shows that cotenancy under a use-or-lose provision in which each party may utilize any unused portion of the other party's capacity by assuming the variable costs, but not the fixed costs, attributable to added production achieves a constraint Pareto optimum under open entry. That is, the equilibrium price converges to long-run average cost. ${ }^{12}$ None of these two papers deal with vertical integration and foreclosure and the latter does not allow for an endogenous entry mode either; that is, it looks only at capacity choice by firms that form a cotenancy prior to building capacity, but it does not allow a firm to enter building capacity outside of cotenancy.

Gaudet and Van Long (1997) show that vertical integration is a dominant strategy when the number of upstream and downstream firms is the same and lower than four, and that multiple

\footnotetext{
${ }^{10}$ Our paper does not deal with the issue of vertical integration as a mechanism for recovering the market power lost from degrading quality of access to the essential facility. Therefore, that literature is not discussed here despite that some of the issues addressed in this paper are touched upon on that literature (see, for instance, Mandy (2000) and Beard et al. (2001)).

${ }^{11}$ The type of contract used by Chen and Ross to derive this result is different from ours. They assume that the sharing contract allows the incumbent to set both the price per-unit of capacity and the quantity of capacity. They show that the optimal price per-unit of capacity is a negative number large enough to induce the entrant to stay out of the market. In order to avoid this problem, they assume a non-negative price per-unit of capacity based on the feasibility of implementing that type of contract in real world.

${ }^{12}$ See Rassenti et al. (1993) for an interesting evaluation of cotenancy rules in a natural gas market experiment. Mainly, they show that cotenancy rules increase efficiency by increasing consumers' surplus and decreasing the pipeline's owners surplus.
} 
equilibria exist for more than four firms, among which full vertical integration is one. They derive their result, just as we do, assuming Cournot competition upstream and downstream, free trade between all parties involved; that is, no market foreclosure is imposed, zero marginal costs and a linear demand function. There are other papers on market foreclosure that are also related but they deal with vertical integration under different types of competition and different assumptions. Mainly, those papers deal with foreclosure but under Bertrand competition eliminating the efficiency gains arising from avoiding double-marginalization and/or assuming the coexistence of integrated and unintegrated firms and/or imposing foreclosure. For instance, the well-know paper by Ordover, Saloner and Salop (1990) shows that vertical foreclosure is possible in equilibrium and therefore vertical integration may have anticompetitive effects. This same result is derived by Chen (2001) under less restrictive assumptions. ${ }^{13}$ Salinger (1988) does not assume away double marginalization, but it imposes the coexistence of integrated and unintegrated firms. Besides the differences in assumptions with most papers in this literature, the foreclosure papers do not deal with the issue of sharing facilities and an endogenous mode of entry.

Our paper is also related to the literature concerning excess capacity as a deterrent instrument. For instance, Spence (1977) and Dixit (1980) show how excess capacity is used as a deterrent instrument. However, in these papers the incumbent chooses its capacity while in our paper we start from a situation in which the incumbent's capacity is already determined and there is excess of capacity.

The rest of the paper is as follows. In the next section, Section 2, the model is presented. In Section 3, we derive the equilibrium market structure under full and partial entry, the optimal entry model, and the welfare properties. In Section 4, some extensions are discussed. In the final section concluding remarks are presented.

\footnotetext{
${ }^{13}$ The reason why less restrictive assumptions are needed is because he realizes that vertical integration may change the pricing incentive of a downstream producer and the incentive of a competitor in choosing an input supplier.
} 


\section{The Basic Model}

The market structure considered initially has one non-integrated upstream firm $U_{1}$-referred to as the incumbent- that owns an important facility and two independent downstream firms, $D_{1}$ and $D_{2}$. There is also firm $U_{2}$-referred to as the entrant- entering the market upstream. Entry upstream requires either buying access to the incumbent's facility, ${ }^{14}$ or building a facility at a fixed cost $K{ }^{15}$ Each upstream firm $U_{i}, i=1,2$, supplies a homogeneous input to downstream firms denoted by $z_{i}$, and each downstream firm produces a final good denoted by $q_{i}, i=1,2$. Thus, upstream firms confront a derived demand given by the amount of input required by downstream firms. For the sake of simplicity, as commonly done in the literature, a constant return to scale technology of fixed proportions downstream is assumed in which one unit of the final good requires one unit of the input $z_{i}$. Thus, $q_{i}=z_{i}$.

The only cost that downstream firms face in order to produce a unit of the final good is the price paid for a unit of input; that is, the cost of other inputs in the downstream market is normalized to zero, and all downstream firms are assumed to be symmetric. Thus, downstream firm $D_{i}$ 's marginal cost is constant and equal to $c_{i}$, where $c_{i}$ is firm $D_{i}$ 's price paid for each unit of input.

The production of $z_{i}$ units of input requires $y_{i}$ units of capacity coming from a facility. A constant return to scale technology of fixed proportions in input production in which each unit of input requires one unit of capacity is assumed. Thus, $z_{i}=y_{i}$.

The facility when combined with other inputs can produce units of capacity according to the cost function $m_{i} y_{i}$, where $m_{i}$ is the marginal cost of each unit of capacity. Because it is assumed that the transfer price for each unit of capacity is set to the efficient level, the marginal cost of producing one unit of input faced by firm owning an important facility is $m_{i}$. In what follows it is assumed that $m_{1} \geq m_{2}$; that is, the entrant's facility is at least as efficient as the

\footnotetext{
${ }^{14}$ The incumbent's capacity is assumed to be unlimited. In the robustness section the consequences of having limited capacity are discussed.

${ }^{15}$ We do not allow the incumbent to built a new facility as entry deterrence mechanism (see, e.g., Spence, 1977 and Dixit, 1980).
} 
incumbent's facility. ${ }^{16}$

The timing of decisions is as follows. At stage 1, the market is liberalized and the entrant decides whether to enter or not. At stage 2, the incumbent makes a take-it-or-leave it offer to supply as many units of capacity as the entrant wants at a price $r$ per-unit of capacity. If the entrant accepts, it does not build a facility while if it rejects the offer, it builds one. At stage 3 , upstream firms have an initial opportunity to acquire one of the downstream firms, $D_{1}$ and $D_{2}$. If there is a merger, it is assumed to be between firms $U_{i}$ and $D_{i}$ and the merged firm is denoted by $F_{i}$. At the next stage, stage 4, upstream firms choose the amount of input to be produced, and at the final stage, downstream firms choose the amount of final good to be produced.

\section{The Analysis}

\subsection{Preliminaries}

The inverse demand function that downstream firms confront is assumed to be of the following form: ${ }^{17}$

$$
P(Q)=a-b Q, a \geq 0 \text { and } b \geq 0
$$

where $Q=q_{i}+q_{j}$.

Since downstream firms compete à-la-Cournot, firm $D_{i}$ chooses to produce the amount of final good that maximizes its profit given by: $\pi_{i}^{D}(n)=(a-b Q) q_{i}-c_{i}(n) q_{i}$, where $n \in\{0,1,2\}$ represents the number of integrated firms. It is straightforward to verify that in equilibrium each downstream firm $D_{i}$ produces $q_{i}(n)=\frac{1}{3 b}\left(a-2 c_{i}(n)+c_{j}(n)\right)$ and has a profit equal to:

$$
\pi_{D_{i}}(n)=\frac{\left(a-2 c_{i}(n)+c_{j}(n)\right)^{2}}{9 b} .
$$

\footnotetext{
${ }^{16}$ This may be justified in several ways. For instance, since the last time that the upstream monopoly upgraded its facility and the time of liberalization new technologies has been invented.

${ }^{17}$ Most results do not depend on this assumption. Yet, this simplification allows to obtain closed-form solutions that greatly facilitates the equilibrium and welfare analysis.
} 
In order to ensure positive quantities in equilibrium for all non-negative marginal costs, it is assumed that $a \geq 2 m_{1}$.

In what follows, define $Z=z_{1}+z_{2}$ as the total input production, and notice that since downstream firms transform upstream input on final output on a one-to-one basis, in equilibrium, $Z=Q$ must hold.

Finally, under either full or partial entry there are four possible market structures that may arise. These are: (i) No integration; (ii) full integration; (iii) integration by firms $U_{i}$ and $D_{i}$ only; and (iv) integration by firms $U_{j}$ and $D_{j}$ only.

\subsection{Full Entry: Duplication of Facilities}

In this case each upstream firm has its own facility and therefore each upstream firm's marginal cost of production is $m_{i}, i=1,2$.

If no integration takes place downstream firms buy the input in the market at the same price which is determined in equilibrium, and therefore $c_{1}(0)=c_{2}(0)=c(0)$, where 0 stands for zero integrated firms. Given this, the market clearing-price, which is obtained by taking the inverse of $q_{1}(0)+q_{2}(0)$, takes the form $c(0)=a-\frac{3}{2} b Z(0)$. Thus, firm $U_{i}$ chooses $z_{i}(0)$ to maximize $\left(a-\frac{3}{2} b Z(0)-m_{i}\right) z_{i}(0)$.

Given quantity competition it is straightforward to verify that in equilibrium upstream firm $U_{i}$ produces $z_{i}^{F}(0)=\frac{2}{9 b}\left(a-2 m_{i}+m_{j}\right)$, where $F$ stands for full entry. Hence, firm $U_{i}$ 's profit is

$$
\pi_{U_{i}}^{F}(0)=\frac{2\left(a-2 m_{i}+m_{j}\right)^{2}}{27 b}-K_{i}
$$

where $K_{1}=0$ and $K_{2}=K$, and firm $D_{i}$ 's profit is

$$
\pi_{D_{i}}^{F}(0)=\frac{\left(2 a-m_{i}-m_{j}\right)^{2}}{81 b} .
$$

Under full integration, there will then be no demand for inputs from independent upstream firms, therefore this market configuration corresponds to a standard Cournot duopoly, in which the vertically integrated firm $F_{i}$ 's marginal cost is $m_{i}$. It is straightforward to check that the equilibrium quantities are given by $q_{i}^{F}(2)=z_{i}^{F}(2)=\frac{1}{3 b}\left(a-2 m_{i}+m_{j}\right)$, and firm $F_{i}$ 's profit is

$$
\pi_{F_{i}}^{F}(2)=\frac{\left(a-2 m_{i}+m_{j}\right)^{2}}{9 b}-K_{i}
$$


where 2 stands for two integrated upstream firms.

Lastly, consider the case in which only firms $U_{i}$ and $D_{i}$ vertically integrate to form the new firm $F_{i}$. In this case the integrated and the non-integrated downstream firms simultaneously determine the quantities of the final output to be produced. This stage is preceded by the upstream production stage, during which upstream firms compete in quantities taking into account the derived demand resulting from the final good production decisions of the next stage. The decision variable of the non-integrated upstream firm $U_{j}$ is the quantity of the upstream good to be produced, $z_{j}$. The decision that matters for the integrated firm $F_{i}$ at this stage is its net sales to the non-integrated sector, denoted by $s_{i}$ hereafter. We let the quantity of the input traded between the non-integrated firm and the integrated one be determined endogenously with no a priori restrictions on the direction of this trade. That is the integrated firm may, if it so chooses, sell inputs to the non-integrated downstream firm or buy inputs from the non-integrated upstream firm, thereby $s_{i}$ may either be positive or negative. Thus, under this assumption, the total profit of the integrated firm $F_{i}$ is $\left(a-b Q-m_{i}\right) q_{i}+\left(c-m_{i}\right) s_{i}$, where the profit of the non-integrated upstream firm $U_{j}$ is $\left(c-m_{j}\right) z_{j}-K_{j}$, and the profit of the non-integrated downstream firm $D_{j}$ is $(a-b Q-c) q_{j}$.

The following lemma as all following lemmas and propositions are formally proven in the appendix.

Lemma 1 When only firms $U_{i}$ and $D_{i}$ integrate, then $c_{i}^{F}(1)=\frac{1}{16}\left(5 a+5 m_{i}+6 m_{j}\right)>\max \left\{m_{i}, m_{j}\right\}$, $p_{i}^{F}(1)=\frac{1}{16}\left(7 a+7 m_{i}+2 m_{j}\right)$ and $s_{i}^{F}(1)=-\frac{1\left(a+m_{i}-2 m_{j}\right)}{12 b}$.

This lemma shows that the integrated upstream firm buys inputs from the unintegrated upstream firm at the market-clearing price $c_{i}^{F}(1)$ exceeding its own upstream marginal cost of production. This is done for an strategic reason that is to raise the input price paid for by the non-integrated downstream firm, which, in turn, reduces the intensity of competition in the downstream segment. This type of strategy is known as raising rivals costs strategy (Salop and Sheffman, 1987), and it has been studied for the case of cournot oligopolies by Gaudet and Van Long (1997). 
Firm $U_{j}$ 's profit is

$$
\pi_{U_{j}}^{F}(1)=\frac{25\left(a-2 m_{j}+m_{i}\right)^{2}}{384 b}-K_{j}
$$

the independent downstream producer $D_{j}$ obtains

$$
\pi_{D_{j}}^{F}(1)=\frac{\left(a-2 m_{j}+m_{i}\right)^{2}}{64 b}
$$

and the integrated firm gets

$$
\pi_{F_{i}}^{F}(1)=\frac{\left(7 a-9 m_{i}+2 m_{j}\right)^{2}}{256 b}-\frac{\left(a+m_{i}-2 m_{j}\right)\left(5 a-11 m_{i}+6 m_{j}\right)}{192 b}-K_{i} .
$$

The integrated firm's profit has two terms: the first one is the profit from final good production, and the second is the cost of adopting the raising rival cost strategy. As expected this cost is higher for smaller integrated firm marginal cost $m_{i}$ and smaller $b$. This is due to the fact that the raising rival cost strategy requires buying units of input at a price above $m_{i}$, and the smaller $b$ means a more intense downstream competition. The more intense competition downstream, the less profitable it is to raise the rival's cost of production, since the gain from reducing competition downstream by increasing its rival's cost is small relative to the cost of buying inputs at a larger price.

The use of the raising rival cost strategy is costly for the non-integrated firm, so the fact that the integrated firm uses it provides an extra incentive for the non-integrated firm to integrate. Thus, when the quantity of the input traded between the non-integrated firm and the integrated firm is determined endogenously, there are two reasons for vertical integration: the standard one is to avoid double marginalization, and the more novel one is to avoid the consequences of competing with an integrated firm that makes use of a raising rival cost strategy. In fact profit comparisons across different market configurations provide us with the following result.

Proposition 2 If full entry takes place, then in equilibrium there is full vertical integration for all $m_{1} \geq m_{2} \geq 0$. 
This proposition establishes that the only market equilibrium under full entry is for both upstream firms to vertically integrate. This occurs despite the fact that firms are better-off if no one integrates; that is, $\pi_{U_{i}}^{F}(0)+\pi_{D_{i}}^{F}(0)>\pi_{F_{i}}^{F}(2)$ for $i=1,2$. This implies that firms face a prisoner's dilemma because vertical integration is the unique equilibrium, but each firm would be better-off if no one would integrate. The reason is that vertical integration will, by reducing the cost of the input into the downstream production process, increase the degree of competition in the downstream market, thus mitigating the gains from eliminating the double marginalization. ${ }^{18}$

\subsection{Partial Entry: No Duplication of Facilities}

Buying access to the incumbent's facility instead of building a facility has benefits and costs. On one hand, the entrant saves on fixed cost $K$, and on the other hand, the entrant has to buy access to the incumbent's facility, which is the sole provider of capacity. As the only provider of capacity, the incumbent may attempt to exploit its monopoly power. However, the incumbent's power is limited by the fact that the entrant can build its own facility if charged too much for access. How much the incumbent can exploit its monopoly power as a sole provider of access depends on: first, the entrant's cost of building its own facility, second the type of access contracts that are allowed, and third the incumbent's bargaining power.

For the sake of simplicity, it is assumed that incumbent firm sells as many units of capacity $y$ as the entrant wants at a given price $r$ per-unit of capacity, and following Chen and Ross (2001), that the incumbent has all the bargaining power and makes a take-it-or-leave-it offer to the entrant. ${ }^{19}$ Furthermore, in order to guarantee non-negative quantities in each possible market configuration or a positive demand for capacity, in this section we assume that the incumbent never charge a price per-unit of capacity $r$ larger than the monopoly price $\frac{a+m_{1}}{2}$. In

\footnotetext{
${ }^{18}$ As shown by Gaudet and Van Long (1997) in the case in which the marginal cost is zero for all upstream firm's, this is no longer true for an oligopoly with more than 4 firms upstream and downstream. The reason being that when there are several firms in the downstream market the gain from reducing competition in this market cannot compensate the increased marginal cost of production.

${ }^{19}$ The consequences of this assumption are discussed in Section 4.
} 
the next section, we show that in equilibrium this is always the case.

After the two firms have agreed to share the incumbent's facility under the contract terms, each upstream firm has to decide how many units of input to produce, and then each downstream firm chooses final good production. The analysis is much the same as the one under full entry, with the difference being that the entrant's marginal cost of production is $r$ instead of $m_{2}$-that is the price paid for each unit of capacity- and the incumbent firm's profit function is different because it makes a profit equal to $\left(r-m_{1}\right) y$ when it sells $y$ units of capacity to the entrant. Thus, the entrant's problem in each case is the same as when no shared-facility agreement is in place, yet now its marginal cost of production is equal to $r$. So, for the sake of brevity we will focus only on the incumbent's production decision.

Consider first the case in which no firm is vertically integrated. The incumbent chooses $z_{1}$ to maximize $\left(a-\frac{3}{2} b Z-r\right) z_{1}+\left(r-m_{1}\right) z_{2}$, where the second term is the gain from selling $z_{2}$ units of capacity to the entrant. It is easy to verify that the entrants's profit is $\pi_{U_{2}}^{P}(0)=\frac{2}{27 b}\left(a-2 r+m_{1}\right)^{2}$ while the incumbent's profit is

$$
\pi_{U_{1}}^{P}(0)=\frac{2}{27 b}\left[\left(a-2 m_{1}+r\right)^{2}+3\left(r-m_{1}\right)\left(a-2 r+m_{1}\right)\right]
$$

where $P$ stands for partial entry.

An increase in the price per-unit of capacity, on one hand, increases the margin per-unit sold and decreases upstream competition, and on the other, decreases the total amount of units of capacity sold. The former dominates the latter for all $r \leq \frac{a+m_{1}}{2}$, which is the monopoly price.

Firm $D_{i}$ 's profit for $i=1,2$ is

$$
\pi_{D_{i}}^{P}(0)=\frac{\left(2 a-m_{1}-r\right)^{2}}{81 b} .
$$

Consider next the case in which full vertical integration takes place; that is, $n=2$. The incumbent's problem is to choose $z_{1}$ to maximize $\left(a-b Z-m_{1}\right) z_{1}+\left(r-m_{1}\right) z_{2}$.

It is straightforward to verify that firm $F_{2}$ 's profit is

$$
\pi_{F_{2}}^{P}(2)=\frac{\left(a-2 r+m_{1}\right)^{2}}{9 b}
$$


and firm $F_{1}$ 's profit is

$$
\pi_{F_{1}}^{P}(2)=\frac{1}{9 b}\left[\left(a-2 m_{1}+r\right)^{2}+3\left(r-m_{1}\right)\left(a-2 r+m_{1}\right)\right] .
$$

As before the incumbent's total profit is increasing in $r$ for all $r \leq \frac{a+m_{1}}{2}$.

Consider now the case in which the incumbent does not integrate but the entrant does. The incumbent's profit is equal to $\left(c_{2}^{P}(1)-m_{1}\right) z_{1}+\left(r-m_{1}\right) z_{2}$, where $c_{2}^{P}(1)$ is the input market-clearing price when only firms $U_{2}$ and $D_{2}$ integrate vertically.

Because the first-order conditions are the same as when duplication of facilities occurs, the following can be easily shown.

Lemma 3 If only the entrant integrates, then $c_{2}^{P}(1)=\frac{1}{16}\left(5 a+5 r+6 m_{1}\right)>m_{1}, p_{2}^{P}(1)=$ $\frac{1}{16}\left(7 a+7 r+2 m_{1}\right)$ and $s_{2}^{P}(1)=-\frac{1\left(a+r-2 m_{1}\right)}{12 b}$.

Notice that the amount of input that the integrated firm $F_{2}$ buys from the non-integrated upstream firm $U_{1}$ increases with the price paid per-unit of capacity $r$. The reason being simple, the larger its cost of production the lower its cost of using the raising rival cost strategy since the opportunity cost of buying the input in the market is larger.

It also interesting to notice that the amount of input produced by the integrated firm is larger while that produced by the non-integrated firm is smaller than those when both integrate vertically. The reason being the unintegrated firm does not avoid double marginalization and does not counter the cost raising strategy used by the integrated firm. Thus, for a given price per-unit of capacity the incumbent sells more units when only the entrant integrates vertically.

It readily follows from this that the incumbent's profit is given by:

$$
\pi_{U_{1}}^{P}(1)=\frac{25\left(a+r-2 m_{1}\right)^{2}}{384 b}+\left(r-m_{1}\right) \frac{\left(17 a+14 m_{1}-31 r\right)}{48 b}
$$

the independent downstream firm $D_{1}$ obtains

$$
\pi_{D_{1}}^{P}(1)=\frac{\left(a+r-2 m_{1}\right)^{2}}{64 b}
$$


and the integrated firm $F_{2}$ gets

$$
\pi_{F_{2}}^{P}(1)=\frac{\left(7 a-9 r+2 m_{1}\right)^{2}}{256 b}-\frac{\left(5 a-11 r+6 m_{1}\right)\left(a+r-2 m_{1}\right)}{192 b} .
$$

The incumbent's total profit is increasing in $r$ for all $r \leq \frac{186 a+260 m_{1}}{446}$, which is lower than the monopoly price. The reason being that a larger price per-unit of capacity induces the entrant to buy less units of capacity and more units of input, but the combined purchases decrease.

Lastly, consider the case in which the entrant remains as an independent firm and the incumbent integrates vertically. The incumbent chooses $z_{1}$ to maximize $\left(a-b Q-m_{1}\right) q_{1}+$ $\left(c_{1}^{P}(1)-r\right) s_{1}+\left(r-m_{1}\right) z_{2}$, where $s_{1}$ is the integrated firm's net sales to the non-integrated sector and $c_{1}^{P}(1)$ is the input market-clearing price when only firms $U_{1}$ and $D_{1}$ integrate vertically. By the same analysis as when full entry takes place the following can be easily shown.

Lemma 4 If only the incumbent integrates, then $c_{1}^{P}(1)=\frac{1}{16}\left(5 a+5 m_{1}+6 r\right)>m_{1}, p_{1}^{P}(1)=$ $\frac{1}{16}\left(7 a+7 m_{1}+2 r\right)$ and $s_{1}^{P}(1)=-\frac{1\left(a+m_{1}-2 r\right)}{12 b}$.

Notice that the amount of input that the integrated firm $F_{1}$ buys from the non-integrated upstream firm $U_{2}$ decreases with the price charged per-unit of capacity $r$. The higher the price per-unit of capacity, the higher is the non-integrated upstream firm's marginal cost, and therefore the higher is the price at which input can be bought in the market.

It readily follows from this that the entrant's profit is given by:

$$
\pi_{U_{2}}^{P}(1)=\frac{25\left(a-2 r+m_{1}\right)^{2}}{384 b}
$$

the independent downstream firm $D_{2}$ 's gets

$$
\pi_{D_{2}}^{P}(1)=\frac{\left(a-2 r+m_{1}\right)^{2}}{64 b}
$$

and the integrated firm $F_{1}$ 's profit is:

$$
\begin{aligned}
\pi_{F_{1}}^{P}(1)= & \frac{\left(7 a-9 m_{1}+2 r\right)^{2}}{256 b}-\frac{\left(5 a-11 m_{1}+6 r\right)\left(a+m_{1}-2 r\right)}{192 b}+ \\
& \left(r-m_{1}\right) \frac{5\left(a-2 r+m_{1}\right)}{24 b} .
\end{aligned}
$$


The incumbent's total profit is increasing in $r$ for all $r \leq \frac{a+m_{1}}{2}$, which is the monopoly price.

As before when the quantity of the input traded between firms is determined endogenously, the same two benefits that rationalize vertical integration under full entry may explain vertical integration under partial entry. These are: avoid double marginalization, and counter the negative consequences of the raising rival's cost strategy. Under partial entry, however, the incumbent firm has a counterweighting incentive to integrate vertically that arises from selling excess capacity to the entrant. In the next proposition we show however that this counterweighting incentive is not enough to overcome the benefits from vertical integration. Thus, vertical integration is still a dominant strategy. This is formally shown in the next proposition.

Proposition 5 If partial entry takes place, then in equilibrium there is full vertical integration for all $r \in\left[0, \frac{a+m_{1}}{2}\right]$ and $m_{1} \geq 0$.

Thus, in equilibrium, the entry mode does not change the equilibrium market structure. That, vertical integration is still the unique market equilibrium under partial entry.

\subsection{The Optimal Entry Mode}

In this section the optimal entry mode is obtained. Whether full entry or partial entry is optimal depends on the optimal per-unit price of capacity. To derive this price, an assumption concerning how the rents from integration are split between upstream and downstream firms is needed. To simplify the analysis, as usually done in the literature on vertical integration, it is assumed that upstream firms make take-it-or-leave-it offers to downstream firms. This implies that the upstream firm gets the total profit from integration minus the downstream profit when no-integration occurs, conditional on its rival's strategy.

Furthermore, the assumption that the incumbent makes a take-it-or-leave it offer implies that the entrant accepts a price per-unit of capacity $r$ if and only if it is at least as well-off under partial entry as under full entry. This assumption coupled with the results in propositions 2 and 5 implies that in equilibrium the following must hold

$$
\pi_{U_{2}}^{P}(2) \geq \pi_{U_{2}}^{F}(2) .
$$


In what follows, it is assumed that the entrant chooses to enter in the absence of a sharedfacility agreement for all $K$. That is the fixed cost $K$ is lower than $\bar{K}$, where $\bar{K}$ is the maximum fixed cost at which the entrant makes non-negative profits under full integration and full entry. Formally, $\bar{K}$ satisfies the following $\pi_{U_{2}}^{F}(2) \equiv \pi_{F_{2}}^{F}(2)-\pi_{D_{2}}^{F}(1)=0 .{ }^{20}$ If $K$ were to be larger than $\bar{K}$, then the entrant would not choose a full entry mode and the incumbent would not have an incentive to share its facility with the entrant. Thus, we will observe neither entry nor shared facilities for $K>\bar{K}$.

In this case, the incumbent solves the following problem:

$$
\begin{aligned}
& \max _{r \geq 0} \pi_{U_{1}}^{P}(2) \\
& \text { subject to } \pi_{U_{2}}^{P}(2) \geq \pi_{U_{2}}^{F}(2),
\end{aligned}
$$

where the objective function is the incumbent's rent when full vertical integration occurs, and the constraint ensures that the entrant is better-off using the incumbent's facility than building its own facility.

Notice that for any given $r$ the constraint is easier to satisfy the larger is the fixed cost $K$, since the entrant's rent from building its own facility decreases with $K$, and its willingness to pay for each unit of capacity increases with the fixed cost since by buying access to the incumbent's facility the entrant's cost savings increase. In fact, when the fixed cost is zero, the most the entrant will be willing to pay for each unit of capacity is the upstream marginal cost of production of a new facility $m_{2}$.

In addition, the incumbent's rent function is strictly increasing in $r$ for all $r \leq \frac{a+m_{1}}{2}$. This, added to the fact that the entrant is willing to pay more as the fixed cost increases imply that the larger the fixed cost $K$, the higher the incumbent's profit. Therefore, the incumbent prefers to share its facility with the entrant when the fixed cost is sufficiently large. How large the fixed cost is depends on the difference between upstream marginal costs of production since when the incumbent's facility is shared, total industry output is produced using the less efficient facility, and therefore with a higher variable cost of production.

This is captured in the next proposition, where the optimal price per-unit of capacity is also

\footnotetext{
${ }^{20} \bar{K} \equiv \frac{55}{576 b}\left(a-2 m_{2}+m_{1}\right)^{2}$.
} 
derived.

Proposition 6 (i) In equilibrium full entry and full integration is observed for all $K^{*} \leq K,{ }^{21}$ while partial entry and full vertical integration is observed for all $K^{*}<K \leq \bar{K}$; (ii) the equilibrium price per-unit of capacity, denoted by $r^{*}$, is set to $\frac{a+m_{1}}{2}-\frac{1}{2}\left(\left(a-2 m_{2}+m_{1}\right)^{2}-\frac{576}{55} b K\right)^{\frac{1}{2}}$ for $K \leq \hat{K}$ and equal to $\frac{302 a+356 m_{1}}{658}$ for $K>\hat{K}$; and (iii) $Q^{F}(2) \geq Q^{P}(2)$.

By sharing the facility with entrant, the incumbent curbs the potential competition by the entrant by means of inducing it to produce inputs at a higher marginal cost; i.e., $r^{*}>m_{2}$ for all $K>0$, and takes advantage of the entrant's incentive to raise its downstream rival's cost. Curbing competition is the outcome from avoiding the entrance of a more efficient upstream firm when $m_{2}<m_{1}$, and of charging an access price above the entrant's upstream marginal cost; that is $r^{*}>m_{2}$. These two effects result in a reduction of output. ${ }^{22}$

\subsection{Welfare Analysis}

In this section the efficiency of partial entry relative to full entry is studied. First notice that partial entry is always more socially efficient than no entry. This is simply because partial entry expands output beyond the level before liberalization without incurring new fixed costs. However, this is not the whole story.

Partial entry affects total welfare through two channels. First, it avoids duplication of facilities, and hence it generates a cost saving of $K$, but this results in an increasing variable cost of production since $m_{1} \geq m_{2}$. Second, it decreases the intensity of competition since the price charged per unit of capacity is larger than the entrant's marginal cost when building its own facility. That is $r^{*}>m_{2}$. The first effect can either increase or decrease welfare while the second decreases it.

\footnotetext{
${ }^{21} K^{*}=0$ for $m_{2}=m_{1}$.

${ }^{22}$ This effect is similar to what Chen and Ross (2000) call the collusion effect. The main differences are that in their paper, the price per-unit of capacity is set to zero and collusion is achieved by restricting the entrant's capacity to a level below the one that the entrant will use if it were to build a facility, and that the incumbent and the entrant have the same upstream marginal cost of production.
} 
Notice first that $Q^{F}(2)=\frac{1}{3 b}\left(2 a-m_{1}-m_{2}\right) \geq Q^{P}(2)=\frac{1}{3 b}\left(2 a-m_{1}-r^{*}\right)$ because $r^{*} \geq$ $m_{2}$. That is, consumers' welfare is lower under a shared-facility agreement because total output is restricted relative to that under full entry since the variable cost of production is larger.

Total welfare when each firm builds its own facility is $W^{F}(2) \equiv \pi_{F_{1}}^{F}(2)+\pi_{F_{2}}^{F}(2)+\frac{b\left[Q^{F}(2)\right]^{2}}{2}$, while under partial entry is $W^{P}(2) \equiv \pi_{F_{2}}^{P}(2)+\pi_{F_{2}}^{P}(2)+\frac{b\left[Q^{P}(2)\right]^{2}}{2}$.

It is straightforward to verify that the difference in total welfare under full entry and total welfare under partial entry before subtracting fixed costs, $\triangle W(K) \equiv W^{F}(2)-W^{P}(2)+K$, is increasing with and convex in $K$ for all $K \leq \hat{K}$ and constant with $K$ for all $K>\hat{K}$. The reason being that the price per-unit of capacity increases with fixed costs for all $K \leq \hat{K}$ and is constant otherwise. Thus, for $K>\hat{K}, \triangle W(K)$ decreases with $K$.

For $K \leq \hat{K}$, a key determinant of $\triangle W(K)$ is the difference between the incumbent and the entrant's upstream marginal cost, denoted by $\triangle m \equiv m_{1}-m_{2}$. The larger $\triangle m$, the more likely that full entry yields a larger total welfare than partial entry since the variable cost of production is larger under partial entry.

Then the following proposition is shown in the appendix.

Proposition 7 (i) If $\triangle m \geq 0.313\left(a-m_{1}\right)$, then full entry is efficient relative to partial entry for all $K$; (ii) if $0.313\left(a-m_{1}\right)>\Delta m \geq 0.266\left(a-m_{1}\right)$, full entry is efficient relative to partial entry for all $K \in\left[0, K_{L}\right] \cup\left[K_{H}, \bar{K}\right]$; (iii) if $0.266\left(a-m_{1}\right)>\triangle m \geq 0.262\left(a-m_{1}\right)$, then full entry is efficient relative to partial entry for all $K \in\left[0, K_{L}\right] \cup\left[K_{H}, K^{* *}\right]$; and (iv) if $\triangle m<0.2621\left(a-m_{1}\right)$, then full entry is efficient relative to partial entry for all $K \in\left[0, K_{L}\right]$.

This proposition provides several interesting results. When the difference between upstream marginal production costs is large, full entry is always efficient relative to partial entry, yet it is not always observed since $K^{*}<\bar{K}$. In addition, when full entry is observed, it is efficient since $K_{L}>K^{*}$. Whereas when the difference between upstream marginal production costs is small, partial entry is efficient for fixed cost levels in an intermediate range, while full entry is efficient for either small or large fixed cost levels. That full entry is efficient for small fixed cost levels is relatively obvious, but that full entry is can also efficient for large fixed cost levels is not. The reason being that the price per-unit of capacity rises at an increasing rate with the fixed cost 
level up to $\hat{K}$. This implies that for a large fixed cost level, the decrease in consumers' welfare outweighs the increase in the incumbent's profit.

A important lesson from the welfare analysis is that the market itself is able to solve the trade-off between saving fixed costs and soften downstream competition efficiently in many situations.

\section{Robustness}

In order to reduce the complexity of the issue studied many simplifying assumptions were made and a thorough analysis of robustness will take a paper in its own right. Thus, in this section the main features of the model are kept and we modify only two of the many assumptions made. First, a limited capacity to the incumbent's facility is imposed, and second, it is assumed that the entrant has all the bargaining power. ${ }^{23}$

\subsection{Capacity Constraints}

The results derived in propositions 6 and 7 were obtained under the assumption that facilities have an unlimited capacity, which in many circumstances is not a good working assumption. In this section we will explore how our results change when the incumbent's capacity is not enough to serve the entrant's demand for capacity, but when each upstream firm has its own facility there are no capacity constraints; that is, each facility has enough capacity to serve its demand under each of the four market structures.

Under full entry, the unique market equilibrium is still full vertical integration since there are no capacity restrictions. Whereas under partial entry, there are capacity limits that may not allow the incumbent to reap the efficiency gains from vertical integration. Furthermore, the incumbent's opportunity cost from using a unit of capacity at cost $m_{1}$ is the price that the integrated sector is willing to pay for that unit, which may be larger than $m_{1}$. In fact, it is simple to show that when the entrant does not built a facility, vertical integration by the entrant and non-vertical integration by the incumbent is the unique market equilibrium.

\footnotetext{
${ }^{23}$ The formal details of the analysis in this section are available upon request.
} 
As before the equilibrium price per-unit of capacity depends on the fixed cost level, and therefore when the latter is sufficiently large sharing the incumbent's facility is chosen over full entry. This implies that full entry is an equilibrium for low fixed-cost levels even when $m_{1}=m_{2}$. Thus the main differences with the model in which there is no capacity constraint is that the incumbent will never choose to integrate with a downstream firm upon entry and that full entry is an equilibrium for low fixed cost levels for all possible values of $m_{2}$.

\subsection{Bargaining Power}

It is relatively obvious that our results are partially driven by the assumption that the incumbent has all the bargaining power. Here, we analyze the opposite case in which the entrant has all the bargaining power, and therefore it makes a take-it-or-leave-it offer to the incumbent to buy as many units of capacity as it wants at price $r$ per-unit of capacity.

Because the entrant has all the bargaining power, upon entry it will offer to the incumbent to buy as many units of capacity as it wants at a price that leaves the incumbent indifferent between accepting and rejecting to share its facility with the entrant. That is, the entrant will offer the lowest possible price which is the incumbent's upstream marginal cost production $m_{1}$, and therefore, if partial entry occurs the market configuration will be full vertical integration.

If $m_{2}=m_{1}$, by sharing the facility the entrant can save the fixed cost and get the input at the same price as when it builds its own facility. Thus, sharing facilities is the only equilibrium and it is efficient. Whereas when $m_{2}<m_{1}$, there exists a fixed cost level such that above that level partial entry is the only equilibrium and below that, full entry is the unique equilibrium. ${ }^{24}$ Because the price per-unit of capacity is independent of fixed costs, full entry is efficient when the fixed cost level is lower than certain threshold and it is larger otherwise.

This suggests that if neither the incumbent nor the entrant has all the bargaining power the results derived under the assumption that the incumbent has all the bargaining power are qualitatively the same, but since the optimal price per-unit of capacity will be smaller, partial entry plus full integration would take place more often, and welfare would be larger because

\footnotetext{
${ }^{24}$ It is easy to verify that the fixed cost level threshold is $\frac{55}{144} \frac{\left(a-m_{1}\right)\left(m_{1}-m_{2}\right)}{b}$.
} 
the price per-unit of capacity will be set at lower level.

\section{Conclusions}

This paper has studied liberalization in a market in which initially there is an unintegrated monopoly upstream that owns a facility and two downstream firms. It has shown that when the cost of building a new facility is small, facility-based competition and full vertical integration will take place, while when it is sufficiently large sharing facilities and full vertical integration will take place. Shared facilities is pro-competitive relative to the initial situation but it is anticompetitive relative to facility-based competition. However, the latter is efficient for fixed cost levels in an intermediate range, but, when observed, facility-based competition is always efficient. Thus, the market itself is able to solve the trade-off between saving fixed costs and softening downstream competition efficiently in many situations.

The results provide a rationale for the liberalization of industries with characteristics of natural monopoly as a complimentary measure, if not as an alternative to direct regulation. In fact, unregulated privatization is a relevant policy design under facility based competition. In practice, however, to which industries this can be applied is a question that demands a case by case analysis that is out of the scope of this paper. Liberalization may also be useful as an antitrust remedy, especially when the costs of replicating the incumbent's facility are small or the difference in efficiency between the incumbent and the entrant's facility is significant.

The analysis here has presented a model that enriches the case for liberalization of natural monopolies as an alternative policy to direct regulation, but some caveats are in order. For instance, it is commonly argued that vertical integration may facilitate collusion, yet collusion issues have been set aside, and we do not consider the issue of degrading quality of access to the incumbent's facility. The incentive to degrade quality may decrease the benefits of liberalization and induce the authorities to impose some type of regulation. 


\section{References}

[1] Beard, T., Kasserman, D., and Mayo, J. (2001). "Regulation, Vertical Integration, and Sabotage", Journal of Industrial Economics, Vol. 29, N 49: 319-333.

[2] Bork, R. (1978). The Antitrust Paradox: A Policy at War with Itself. New York: Basic Books.

[3] Brueckner, J. and Whalen, W. (2000). "The Price Effects of International Airline Alliances", The Journal of Law and Economics, Vol. 43, $\mathrm{N}^{\circ}$ 2: 503-547.

[4] Chen, Z. and Ross, T. W. (2000). "Strategic Alliances, Shared Facilities, and Entry Deterrence", The RAND Journal of Economics, Vol. 31, N 2: 326-344.

[5] Chen, Y. (2001). "On Vertical Merger and Their Competitive Effects", The RAND Journal of Economics, Vol. 32, ํㅜ 4: 667-685.

[6] Dixit, A. (1980). "The Role of Investment in Entry-Deterrence", Economic Journal, Vol. 90: 95-106.

[7] Gale, I. (1994). "Price Competition in Noncooperative Joint Ventures", International Journal of Industrial Organization, Vol. 12: 53-69.

[8] Hendricks, K., Piccione, M., and Tan, G. (1997). "Entry and Exit in Hub-Spoke Networks", The RAND Journal of Economics, Vol. 28, N²: 291-303.

[9] Godek, P.E. and Lopatka, J.E. (1992). “Another Look at Alcoa: Raising Rival's Cost Does Not Improve the View", The Journal of Law and Economics, Vol. 35, N²: 311-335.

[10] Gaudet, G. and Van Long, N. (1997). "Vertical Integration, Foreclosure, and Profits in the Presence of Double Marginalization", Journal of Economics and Management Strategy, Vol. 16: 367-384. 
[11] Kleit, A. and Palsson, H. (1996). "Is There Anti-Competitive Behavior in the Central Canadian Cement Industry?. Testing Arbitrage Cost Hypothesis", Canadian Journal of Economics, Vol. 29, № 2: 343-356.

[12] Levy, D. and Reiffen, D. (1988). "Vertical Integration as Strategic Behavior in a Spacial Setting: Reducing Rivals' Revenue", Federal Trade Commission Bureau of Economics Working Paper $N^{\circ} 165$.

[13] Mandy, D. (2000). "Killing the Goose that May Have Laid the Golden Egg: Only the Data Knows whether Sabotage Pays", Journal of Regulatory Economics, Vol. 17, N²: 157-172.

[14] Muris,T. (2000). "The FTC and the Law of Monopolization", Antirust Law Journal, Vol. 67: 693-723.

[15] Oh, J-G. (1996). "Global Strategic Alliances in the Telecommunication Industry", Telecommunications Policy, Vol. 20, № 9: 713-720.

[16] Park, J-H. and Zhang, A. (2000). "An Empirical Analysis of Global Airline Alliances: Cases in North American Markets", Review of Industrial Organization, Vol. 16: 367-384.

[17] Ordover, J.A., Saloner, G., and Salop, S.C. (1992). "Equilibrium Vertical Foreclosure", American Economic Review, Vol. 80, ํㅜ 2: 127-142.

[18] Pitofsky, R. (2002). "The Essential Facility Doctrine Under United States Antitrust Law", Antitrust Law Journal, Vol. 70: 443-468.

[19] Posner, R. (1976). Antitrust Law: An Economic Perspective, University of Chicago Press.

[20] Reitzes, J. and Levy, D. (1995). "Price Discrimination and Mergers", Canadian Journal of Economics, Vol. 28, № 2: 427-436.

[21] Rassenti, S., Reynolds, S., and Smith, V. (1994). "Cotenancy and Competition in an Experimental Auction Market for a Natural Gas Pipeline", Economic Theory, Vol. 28, N 2: $427-436$. 
[22] Reiffen, D. and Kleit, A. (1990). "Terminal Railroad Revisited: Foreclosure of an Essential Facility or Simply Horizontal Monopoly?", The Journal of Law and Economics, Vol. 33, $\mathrm{N}^{\circ} 2: 419-430$.

[23] Rey, P. and Tirole, J. (2004). "A Primer on Foreclosure", forthcoming in The Handbook of Industrial Organization Vol. 3, Armstrong, M. y R. Porter editors, North Holland.

[24] Salinger, M.A. (1988). "Vertical Mergers and Market Foreclosure", Quarterly Journal of Economics, Vol. 103: 345-356.

[25] Salop, S.C. and Scheffman, D.T. (1987). "Cost-Raising Strategies", Journal of Industrial Economics, Vol. 36, № 2: 19-34.

[26] Spence, A. (1977). "Entry, Capacity, Investment, and Oligopolistic Pricing", Bell Journal of Economics, Vol. 8: 534-544.

[27] U.S. Federal Trade Commission and Department of Justice (2000). Guidelines for Collaboration Among Competitors, Washington D.C.

\section{A Appendix}

\section{Proof. of Lemma 1.}

It follows from the equilibrium conditions for the downstream market that the optimal quantities are given by $q_{j}^{F}(1)=\frac{1}{3 b}\left(a-2 c+m_{i}\right)$ and $q_{i}^{F}(1)=\frac{1}{3 b}\left(a-2 m_{i}+c\right)$, where 1 stands for only one integrated upstream firm.

The market demand for the upstream input comes from the non-integrated downstream firm $D_{j}$. This firm will be supplied by the non-integrated upstream firm $U_{j}$ that produces $z_{j}$ and potentially by the integrated upstream firm $U_{i}$ that have net sales $s_{i}$. The competition at the upstream state is therefore subject to the derived inverse demand

$$
c_{j}(1)=\frac{a+m_{i}-3 b\left(s_{i}+z_{j}\right)}{2} .
$$


Using the envelope theorem, the equilibrium conditions in this case are then given by

$$
\begin{gathered}
a+m_{i}-2 m_{j}-3 b s_{i}-6 b z_{j} \leq 0, \\
\frac{2}{3} c(1)-\frac{1}{3} a-\frac{1}{3} m_{i}+s_{i}\left(-\frac{3}{2} b\right) \leq 0 .
\end{gathered}
$$

It readily follows from these equilibrium conditions that the optimal quantities are:

$$
\begin{gathered}
z_{j}^{F}(1)=\frac{5\left(a-2 m_{j}+m_{i}\right)}{24 b}, \\
s_{i}^{F}(1)=-\frac{1\left(a+m_{i}-2 m_{j}\right)}{12 b}, \\
z_{i}^{F}(1)=\frac{17 a-31 m_{i}+14 m_{j}}{48 b} .
\end{gathered}
$$

Thus, the input price is $c_{i}^{F}(1)=\frac{1}{16}\left(5 a+5 m_{i}+6 m_{j}\right)>\max \left\{m_{i}, m_{j}\right\}$ and the final good price is $p_{i}^{F}(1)=\frac{1}{16}\left(7 a+7 m_{i}+2 m_{j}\right)$.

\section{Proof. of Proposition 2.}

Consider first firms $U_{i}$ and $D_{i}$ 's best response to non-integration by firms $U_{j}$ and $D_{j}$. Notice that

$$
\begin{gathered}
\pi_{F_{i}}^{F}(1)-\left[\pi_{U_{i}}^{F}(0)+\pi_{D_{i}}^{F}(0)\right]= \\
\frac{869 a^{2}-2390 a m_{i}+652 a m_{j}+1349 m_{i}^{2}-308 m_{i} m_{j}-172 m_{j}^{2}}{20736 b}
\end{gathered} .
$$

Notice that if $m_{i}=m_{j}=m$, then $\pi_{F_{i}}^{F}(1)-\left[\pi_{U_{i}}^{F}(0)+\pi_{D_{i}}^{F}(0)\right]=\frac{869}{20736} \frac{a^{2}-2 a m+m^{2}}{b}>0$. Suppose that $i=1$ and $j=2$. Then, $\pi_{F_{1}}^{F}(1)-\left[\pi_{U_{1}}^{F}(0)+\pi_{D_{1}}^{F}(0)\right]$ is strictly increasing in $m_{2}$ and at $m_{2}=0$ is equal to $\frac{869 a^{2}-2390 a m_{1}+1349 m_{1}^{2}}{20736 b}$. Notice that this decreases in $m_{1}$ and that at $m_{1}=\frac{a}{2}$ is equal to $\frac{5}{9216} \frac{a^{2}}{b}>0$. Thus, vertical integration is the best response to non-integration by firms $U_{2}$ and $D_{2}$ for all $m_{1}$ and $m_{2}$.

Suppose next that $i=2$ and $j=1$. Then, $\pi_{F_{2}}^{F}(1)-\left[\pi_{U_{2}}^{F}(0)+\pi_{D_{2}}^{F}(0)\right]$ is strictly decreasing in $m_{2}$ and at $m_{2}=m_{1}$, is equal to $\frac{869}{20736} \frac{a^{2}-2 a m_{1}+m_{1}^{2}}{b}>0$. Thus, vertical integration is the best response to non-integration by firms $U_{1}$ and $D_{1}$ for all $m_{1}$ and $m_{2}$.

Consider next firms $U_{i}$ and $D_{i}$ 's best response to integration by firms $U_{j}$ and $D_{j}$. Notice that

$$
\pi_{F_{i}}^{F}(2)-\left[\pi_{U_{i}}^{F}(1)+\pi_{D_{i}}^{F}(1)\right]=\frac{35}{1152} \frac{\left(a-2 m_{i}+m_{j}\right)^{2}}{b}>0
$$


Given that the difference in joint profits is positive, vertical integration is the best response to integration by firms $U_{j}$ and $D_{j}$ for all $m_{i}$ and $m_{j}$.

These two things together imply that vertical integration is a dominant strategy.

\section{Proof. of Lemma 3.}

Applying the envelope theorem, the first-order conditions are given by:

$$
\begin{aligned}
& z_{1}: a+r-2 m_{1}-3 b s_{2}-6 b z_{1}=0 \\
& s_{2}: \frac{1}{3}\left(a+r-3 b\left(s_{2}+z_{1}\right)\right)-\frac{1}{3} a-\frac{1}{3} r-\frac{3}{2} b s_{2}=0 .
\end{aligned}
$$

Solving these out, one gets the following:

$$
\begin{gathered}
z_{1}^{P}(1)=\frac{5\left(a+r-2 m_{1}\right)}{24 b}, \\
s_{2}^{P}(1)=-\frac{1\left(a+r-2 m_{1}\right)}{12 b}, \\
z_{2}^{P}(1)=\frac{\left(17 a+14 m_{1}-31 r\right)}{48 b} .
\end{gathered}
$$

Plugging this values into the derived demand, one gets $c_{2}(1)$ and $p_{2}^{P}(1)$ as claimed.

\section{Proof. of Lemma 4.}

Applying the envelope theorem, the first-order conditions are given by:

$$
\begin{aligned}
& z_{2}: a+m_{1}-2 r-3 b s_{1}-6 b z_{2}=0 \\
& s_{1}: \frac{1}{3}\left(a+m_{1}-3 b\left(s_{1}+z_{2}\right)\right)-\frac{1}{3} a-\frac{1}{3} m-\frac{3}{2} b s_{1}=0
\end{aligned}
$$

Solving these out, one gets the following:

$$
\begin{gathered}
z_{2}^{P}(1)=\frac{5\left(a+m_{1}-2 r\right)}{24 b}, \\
s_{1}^{P}(1)=-\frac{1\left(a+m_{1}-2 r\right)}{12 b}, \\
z_{1}^{P}(1)=\frac{\left(17 a+14 r-31 m_{1}\right)}{48 b} .
\end{gathered}
$$

Plugging this values into the derived demand, one gets $c_{1}(1)$ and $p_{1}^{P}(1)$ as claimed.

\section{Proof. of Proposition 5.}

Consider first firms $U_{2}$ and $D_{2}$ 's best response to non-integration by firms $U_{1}$ and $D_{1}$. Notice that

$$
\begin{gathered}
\pi_{F_{2}}^{P}(1)-\left[\pi_{U_{2}}^{P}(0)+\pi_{D_{2}}^{P}(0)\right]= \\
\frac{1}{20736 b}\left(869 a^{2}-2390 a r+652 a m_{1}+1349 r^{2}-308 r m_{1}-172 m_{1}^{2}\right)
\end{gathered}
$$


It is easy to check that the difference in joint profits is continuous, strictly convex in $r$, strictly decreasing in $r$ for all $r \leq \frac{2390 a+308 m_{1}}{2698}$, and equal to $\frac{1}{20736} \frac{869 a^{2}+652 a m_{1}-172 m_{1}^{2}}{b}>0$ at $r=0$. Furthermore, notice that this expression has two real roots given by $\left(.489 m_{1}+.511 a,-.261 m_{1}+1.261 a\right)$. The two roots are positive and larger than $\frac{a+m_{1}}{2}$, which is the maximum value allowed for $r$. Thus, vertical integration is the best response to non-integration by firms $U_{1}$ and $D_{1}$ for all $r \leq \frac{a+m_{1}}{2}$.

Consider next firms $U_{2}$ and $D_{2}$ 's best response to integration by firms $U_{1}$ and $D_{1}$. Notice that

$$
\pi_{F_{2}}^{P}(2)-\left[\pi_{U_{2}}^{P}(1)+\pi_{D_{2}}^{P}(1)\right]=\frac{35}{1152 b}\left(a+m_{1}-2 r\right)^{2} .
$$

Given that the difference in joint profits is positive, vertical integration is the best response to integration by firms $U_{1}$ and $D_{1}$ for all $r \leq m_{1}$.

Therefore, vertical integration is a dominant strategy for firms $U_{2}$ and $D_{2}$ all $r \leq \frac{a+m_{1}}{2}$.

Consider now firms $U_{1}$ and $D_{1}$ 's best response to non-integration by firms $U_{2}$ and $D_{2}$. Notice that

$\pi_{F_{1}}^{P}(1)-\left[\pi_{U_{1}}^{P}(0)+\pi_{D_{1}}^{P}(0)\right]=\frac{1}{20736 b}\left(869 a^{2}+364 a r-2102 a m_{1}+404 r^{2}-1172 r m_{1}+1637 m_{1}^{2}\right)$.

It is easy to check that the difference in joint profits is continuous, strictly convex in $r$ and equal to $\frac{869 a^{2}-2390 a m_{1}+1349 m_{1}^{2}}{20736 b}$ when $r=0$, which is always positive since $\frac{a}{2} \geq m_{1}$. Furthermore, this expression has no real roots for $r$. Thus, vertical integration is the best response to nonintegration by firms $U_{1}$ and $D_{1}$ for all $r \geq 0$.

Finally, consider firms $U_{1}$ and $D_{1}$ 's best response to integration by firms $U_{2}$ and $D_{2}$. Notice that

$$
\begin{gathered}
\pi_{F_{1}}^{P}(2)-\left[\pi_{U_{1}}^{P}(1)+\pi_{D_{1}}^{P}(1)\right]= \\
\frac{35 a^{2}+46 a r-116 a m_{1}+11 r^{2}-68 r m_{1}+92 m_{1}^{2}}{1152 b} .
\end{gathered}
$$

This difference is a strictly convex function of $r$ and has two real roots given by

$$
\left\{r=-a+2 m_{1}, r=-\frac{35}{11} a+\frac{46}{11} m_{1}\right\} .
$$


These roots are both negative since $m_{1} \leq \frac{a}{2}$. Thus, given the strict convexity of the profit function, vertical integration is the best response to integration by firms $U_{2}$ and $D_{2}$ for all $r>0$.

\section{Proof. of Lemma 6:}

The incumbent's optimization problem is the following:

$$
\begin{aligned}
& \max _{r \in\left[0, \frac{a+m_{1}}{2}\right]} \pi_{F_{1}}^{P}(2)-\pi_{D_{1}}^{P}(1) \\
& \text { subject to } \pi_{F_{2}}^{P}(2)-\pi_{D_{2}}^{P}(1) \geq \pi_{F_{2}}^{F}(2)-\pi_{D_{2}}^{F}(1),
\end{aligned}
$$

where

$$
\pi_{F_{1}}^{P}(2)-\pi_{D_{1}}^{P}(1)=\frac{55 a^{2}-412 a m_{1}+302 a r+28 m_{1}^{2}+356 r m_{1}-329 r^{2}}{576 b}
$$

and that

$$
\pi_{F_{2}}^{P}(2)-\pi_{D_{2}}^{P}(1)=\frac{55}{576} \frac{\left(a-2 r+m_{1}\right)^{2}}{b} \text { and } \pi_{F_{2}}^{F}(2)-\pi_{D_{2}}^{F}(1)=\frac{55}{576} \frac{\left(a-2 m_{2}+m_{1}\right)^{2}}{b}-K
$$

It is straightforward to show that the solution to this problem when the constraint is ignored is $r=\frac{302 a+356 m_{1}}{658}<\frac{a+m_{1}}{2}$. Thus, if the entrant's constraint is satisfied at $r=\frac{302 a+356 m_{1}}{658}$, the optimal solution for problem PFVI, denoted by $r(2)$, is given by $\frac{302 a+356 m_{1}}{658}$. Because the objective function is strictly concave and increasing for all $r \leq \frac{302 a+356 m_{1}}{658}$ and the restriction is strictly convex and decreasing in $r$ for all $r \leq \frac{a+m_{1}}{2}$, the optimal $r^{*}$ is set to the minimum between

$$
\min \left\{\frac{a+m_{1}}{2}-\frac{1}{2}\left(\left(a-2 m_{2}+m_{1}\right)^{2}-\frac{576}{55} b K\right)^{\frac{1}{2}}, \frac{302 a+356 m_{1}}{658}\right\}
$$

where the first entry is the $r$ that satisfies firm $U_{2}$ 's profit constraint with equality.

Let define $\hat{K}$ as the capital level that solves the following

$$
\frac{a+m_{1}}{2}-\frac{1}{2}\left(\left(a-2 m_{2}+m_{1}\right)^{2}-\frac{576}{55} b K\right)^{\frac{1}{2}}=\frac{302 a+356 m_{1}}{658} .
$$

Thus,

$$
\hat{K}=\frac{55\left(26878 a^{2}+54485 a m_{1}+26878 m_{1}^{2}-108241 a m_{2}+108241 m_{2}^{2}-108241 m_{2} m_{1}\right)}{15586704 b} .
$$


This implies that $r^{*}$ is equal to $\frac{a+m_{1}}{2}-\frac{1}{2}\left(\left(a-2 m_{2}+m_{1}\right)^{2}-\frac{576}{55} b K\right)^{\frac{1}{2}}$ for $K \leq \hat{K}$ and equal to $\frac{302 a+356 m_{1}}{658}$ for $K>\hat{K}$. $\hat{K}$ is lower than $\bar{K}$ since $\frac{a+m_{1}}{2}-\frac{1}{2}\left(\left(a-2 m_{2}+m_{1}\right)^{2}-\frac{576}{55} b K\right)^{\frac{1}{2}}$ at $K=\bar{K}$ is equal to $\frac{a+m_{1}}{2}$.

For full integration and partial entry to be an equilibrium of the whole game, firm $U_{1}$ must be better-off sharing its facility with the entrant than when upon entry firm $U_{2}$ builds its own facility; that is, $\pi_{U_{1}}^{P}(2)-\pi_{U_{1}}^{F}(2) \geq 0$.

Notice that $\pi_{U_{1}}^{P}(2)-\pi_{U_{1}}^{F}(2)$ is equal to

$$
\frac{9 a^{2}-228 a m_{1}+320 a r-156 m_{1}^{2}+320 m_{1} r-320 r^{2}-110 a m_{2}+220 m_{2} m_{1}-55 m_{2}^{2}}{576 b},
$$

which is strictly concave in $r$ and strictly increasing in $r$ for all $r \leq \frac{a+m_{1}}{2}$. If we evaluate this in the optimal price per-unit of capacity $r^{*}$, for all $K \leq \hat{K}$ is equal to

$$
\frac{33 a^{2}-836 a m_{1}-572 m_{1}^{2}+770 a m_{2}-1375 m_{2}^{2}+1980 m_{1} m_{2}+3072 b K}{2112 b},
$$

while for $K>\hat{K}$ is equal to

$$
\frac{9575129 a^{2}-7243748 a m_{1}-8284636 m_{1}^{2}-11906510 a m_{2}+23813020 m_{2} m_{1}-5953255 m_{2}^{2}}{62346816 b} .
$$

Because $\pi_{U_{1}}^{P}(2)-\pi_{U_{1}}^{F}(2)$ is positive ${ }^{25}$ for all $K>\hat{K}$ and strictly increasing in $K$ for all $K \leq \hat{K}$, there exists a $K$, denoted by $K^{*}$, and equal to

$$
K^{*} \equiv \begin{cases}\frac{11\left[\left(70 a+55 m_{1}-125 m_{2}\right) \triangle m-3\left(a-m_{1}\right)^{2}\right]}{3072 b} & \text { for } \triangle m \geq \frac{a-m_{1}}{25} \\ 0 & \text { for } \triangle m<\frac{a-m_{1}}{25}\end{cases}
$$

such that $\pi_{U_{1}}^{P}(2)-\pi_{U_{1}}^{F}(2)$ is positive for all $K>K^{*}$.

\section{Proof. of Proposition 7.}

Notice first that for $K \leq K^{*}$, consumer welfare is larger under full entry since $r^{*}>m_{2}$ ", downstream profits are also larger under full entry since $r^{*}>m_{2}$, the incumbent firm's profit is

\footnotetext{
${ }^{25} \pi_{U_{1}}^{P}(2)-\pi_{U_{1}}^{F}(2)$ is positive for all $K>\hat{K}$ since it is a concave function of $m_{2}$ and has two real roots given by: $-2.615 a+3.615 m_{1}$ and $.615 a+.385 m_{1}$. The former is negative while the latter is positive. This gurantees that $\pi_{U_{1}}^{P}(2)-\pi_{U_{1}}^{F}(2)$ is positive for all $m_{2} \in\left[0, m_{1}\right]$.
} 
larger under full entry, and the entrant is indifferent between full entry and partial entry since $r^{*}$ is set to satisfy $\pi_{U_{2}}^{P}(2)=\pi_{U_{2}}^{F}(2)$. Thus, total welfare is larger under full entry than partial entry for all $K \leq K^{*}$.

Given the results in Proposition 6, total welfare under full entry and full integration minus total welfare under partial entry and full integration before subtracting the fixed cost, $\triangle W(K)$, is given by:

$$
\frac{6 m_{1}^{2}-14 m_{2} m_{1}+6 a m_{1}+11 m_{2}^{2}-8 a m_{2}+2 a r+r^{2}-4 r m_{1}}{18 b}
$$

Notice that this is a strictly increasing function of $r$ and since $r^{*}$ is increasing in $K$ for all $K \leq \hat{K}, \triangle W(K)$ is increasing in $K$. In addition, $\triangle W(K)-K$ is strictly convex in $K$, equal to $\frac{1}{3 b}\left(a-2 m_{2}+m_{1}\right) \triangle m \geq 0$ at $K=0$, and equal to

$$
\frac{99846 m_{1}^{2}-293797 m_{1} m_{2}+94105 a m_{1}+170093 m_{2}^{2}-46389 a m_{2}-23858 a^{2}}{742224 b}
$$

at $K=\hat{K}$.

Notice that this function is strictly convex in $m_{2}$, decreasing in $m_{2}$ for all $m_{2} \leq m_{1}$ and is equal to $-\frac{11929}{371112} \frac{\left(a-m_{1}\right)^{2}}{b}<0$ at $m_{2}=m_{1}$. Thus, it is easy to verify that $\triangle W(\hat{K})-\hat{K}>0$ for all $\triangle m>0.262\left(a-m_{1}\right)$.

Furthermore, due to the strict convexity of $\triangle W(K)-K$ for all $K \leq \hat{K}$ with respect to $K$, $\triangle W(K)-K$ has two roots, denoted by $K_{L}$ and $K_{H}$ respectively, given by:

$$
\frac{55\left[\begin{array}{c}
\left(100 a-155 m_{2}+55 m_{1}\right) \Delta m+13\left(a-m_{2}\right)^{2} \pm \\
\left(a-m_{1}\right)\left(169\left(a-m_{1}\right)^{2}-\left(252 a-924 m_{2}+672 m_{1}\right) \triangle m\right)^{\frac{1}{2}}
\end{array}\right]}{15876 b}
$$

Because the term under the square root is strictly concave in $m_{2}$, these roots are real for all $\triangle m \in\left[0,0.313\left(a-m_{1}\right)\right]$. This implies that welfare under full entry is larger than welfare under partial entry for all $K \leq K_{L}$ and $K>\min \left\{K_{H}, \hat{K}\right\}$ when $\triangle m$ is smaller than $0.313\left(a-m_{1}\right)$, otherwise welfare is always larger under full entry.

Because $\triangle W(\hat{K})-\hat{K}>0$ for all $\Delta m>0.262\left(a-m_{1}\right)$ and $K_{H}$ is real for all $\triangle m<$ $0.313\left(a-m_{1}\right)$. It readily follows that $K_{H} \leq \hat{K}$ for all $\triangle m>0.262\left(a-m_{1}\right)$. 
Finally notice that $\triangle W(K)-K$ is strictly decreasing in $K$ for all $K>\hat{K}$, and therefore $\triangle W(K)-K<0$ for all $K>K^{* *} \equiv \frac{446882 m_{1}^{2}-1515374 m_{1} m_{2}+621610 a m_{1}+1190651 m_{2}^{2}-865928 a m_{2}+122159 a^{2}}{1948338 b}$. $K^{* *}$ is lower than $\bar{K}$ for all $\triangle m<0.266\left(a-m_{1}\right)$.

Putting all these results together the proposition obtains. 